\title{
Leptomeningite e hidrocefalia causadas por Cryptococcus sp. em um cão
}

\author{
Leptomeningitis and hydrocephalus caused by Cryptococcus sp. in a dog \\ Saulo Petinatti Pavarini, Pedro Soares Bezerra Júnior, Adriana da Silva Santos, \\ Luciana Sonne, Eduardo Conceição de Oliveira \& David Driemeier
}

\begin{abstract}
RESUMO
A criptococose é uma micose sistêmica de distribuição mundial que afeta humanos e animais. Em caninos, a enfermidade ocorre principalmente no sistema nervoso central e atinge freqüentemente as leptomeninges. $\mathrm{O}$ caso aqui relatado demonstrou clinicamente ataxia, quedas, tremores musculares e desequilíbrio. Ao exame macroscópico do encéfalo, havia espessamento das leptomeninges e dilatação dos ventrículos laterais, terceiro e quarto ventrículos. Os achados histológicos incluíram leptomeningite e plexo-coroidite granulomatosa difusa e moderada, com grande quantidade de blastoconídios redondos ou ovais, com cápsula espessa e positivas às colorações de mucicarmina de Mayer, ácido periódico de Schiff (PAS) e prata metanamina de Grocott. Dados relativos à patologia, sinais clínicos e possíveis fontes de infecção são discutidos.
\end{abstract}

Descritores: criptococose, leptomeningite, hidrocefalia.

\section{ABSTRACT}

Cryptococcosis is a systemic mycosis that affects humans and animals worldwidely. In dogs, the disease typically affects the central nervous system with involvement of leptomeninges. In this case, the clinical findings were ataxia, seizures, muscle tremors and loss of equilibrium. Thickening of leptomeninges and dilation of the lateral, third and fourth ventricles were observed in the macroscopic examination of the brain. Histological findings included diffuse moderate granulomatous leptomeningitis and choroiditis. In association with the inflammatory lesions, there were large numbers of round and oval blastoconidia with thick capsule and stainable with Mayer's mucicarmine, periodic acid Schiff (PAS) and by Grocott's methenamine silver. Data related to pathology, clinical signs and possible method of infection are presented and discussed.

Key words: cryptococcosis, leptomeningitis, hydrocephalus. 


\section{INTRODUÇÃO}

A criptococose é uma micose sistêmica de distribuição mundial decorrente da infecção por leveduras sapróbias do gênero Cryptococcus [11]. Dentre as diferentes espécies desse gênero, Cryptococcus neoformans é isolado na maioria dos casos clínicos em humanos e animais [2,4]. Nos animais, as espécies mais comumente afetadas são os caninos e os felinos, ocasionalmente os eqüinos e raramente outras espécies [10].

Cryptococcus spp. é isolado do solo, madeiras em decomposição e excretas de algumas aves, principalmente pombas. Essas aves têm um papel epidemiológico significativo, pois além de serem vetores mecânicos, suas excretas são consideradas um substrato natural para o fungo. Isto se deve à grande quantidade de creatinina e outros constituintes presentes na excreta dessas aves e que promovem a multiplicação e o desenvolvimento do microorganismo [9]. O objetivo do trabalho é relatar um caso de meningite e hidrocefalia por Cryptococcus sp. em um canino.

\section{RELATO DE CASO}

O encéfalo de um canino macho, raça Boxer e com três anos de idade foi encaminhado ao Setor de Patologia Veterinária (SPV) da Universidade Federal do Rio Grande do Sul (UFRGS). O proprietário relatou que nos 45 dias anteriores ao óbito, o animal teve episódios de ataxia, apatia, quedas e tremores musculares. Ao levantar a cabeça, o animal perdia o equilíbrio e apresentava opistótono. Um exame do líquido cefalorraquidiano coletado aos 10 dias do curso da doença revelou pleocitose eosinofílica. Não havia alterações nos exames hematológicos, bioquímicos e na ecografia abdominal. Apesar da administração via oral de $2 \mathrm{mg} / \mathrm{kg}$ de prednisona durante oito dias, o quadro se agravou e evoluiu para o óbito.

Macroscopicamente, havia espessamento das leptomeninges e dilatação dos ventrículos laterais (Figura 1), terceiro e quarto ventrículos. Ao exame histológico, as leptomeninges e plexo coróide apresentavam grande número de blastoconídios redondos ou ovais, medindo cerca de $10 \mu \mathrm{m}$, com cápsula espessa fracamente corada pela hematoxilina e eosina e com brotamentos (Figura 2). Estas estruturas ficaram evidentes pelas colorações de Mucicarmina de
Mayer (Figura 3), Prata Metenamina de Grocott e Ácido Periódico de Schiff (PAS) (Figura 4). Havia leve a moderada inflamação granulomatosa associada e caracterizada por linfócitos, plasmócitos, macrófagos espumosos e células gigantes tipo Langhans. O exame imunoistoquímico para cinomose foi negativo. Outros órgãos não estavam disponíveis para exames.

\section{DISCUSSÃO}

O diagnóstico de criptococose no presente caso foi baseado nas lesões microscópicas e nas características morfológicas do organismo presente nas lesões [1,4]. A presença de blastoconídios com brotamentos, medindo de 2 a 20 micrometros de diâmetro, circundadas por halo claro em cortes corados pela Hematoxilina e Eosina (HE) são consideradas características. Colorações especiais, como as utilizadas no caso, confirmam a identificação morfológica das estruturas observadas no HE [1].

A pleocitose eosinofílica encontrada no exame do líquido cefalorraquidiano tem sido descrita em casos de criptococose. Apesar de descrita, a visualização do agente no líquor não foi possível nesse caso. Dessa forma os resultados dessas análises não permitiram o diagnóstico ante-mortem [2,4-6,9-12].

A criptococose canina é mais freqüente em animais de raças de grande porte, com idade inferior a quatro anos, como observado no presente caso [6,12].

Sinais clínicos como apatia e convulsões são indicativos de envolvimento de estruturas acima do forame magno, sugerindo um processo patológico multifocal no sistema nervoso central $[6,12,13]$. Os sinais clínicos neurológicos apresentados pelo animal são compatíveis com os descritos na criptococose em cães; entretanto, não permitam um diagnóstico clínico.

Embora haja uma predileção pelo envolvimento do sistema nervoso na criptococose canina, muitos pacientes têm evidências de afecção extraneural, que incluem corioretinites, sinusites, linfadenopatia e lesões de pele [3,4,12]. Apenas os sinais neurológicos foram relatados pelo solicitante do exame e apenas o encéfalo foi encaminhado para análise. Portanto, a possibilidade de envolvimento de outros sistemas não pode ser avaliada.

Doenças imunossupressivas e/ou administração de corticosteróides podem desencadear ou exa- 


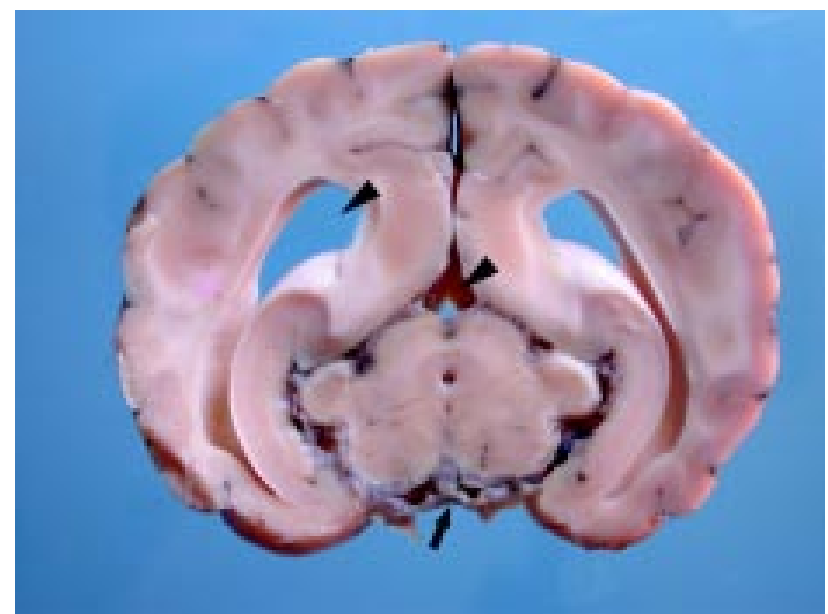

Figura 1. Encéfalo com espessamento das leptomeninges (seta) e dilatação dos ventrículos laterais e quarto ventrículo(cabeça de seta).

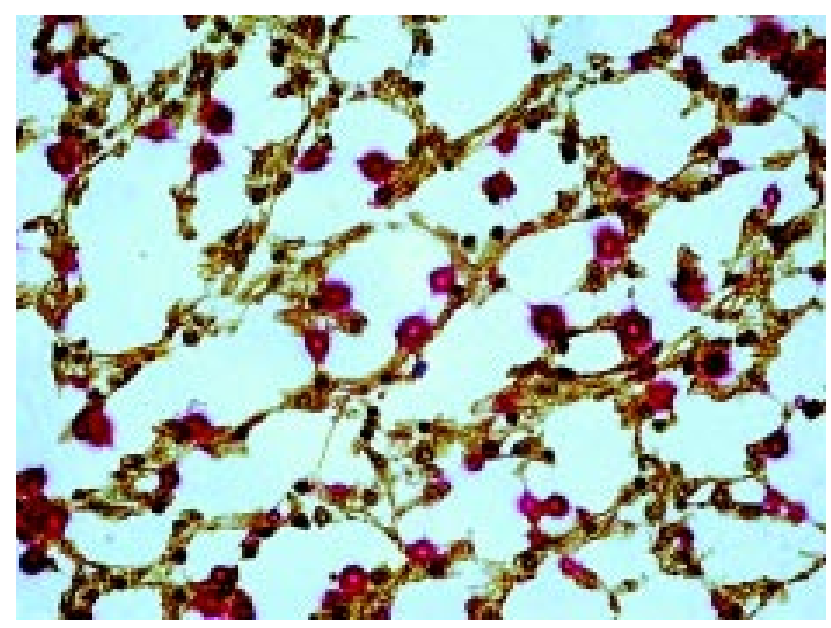

Figura 3. Cápsulas mucicarmina positivas, de coloração vermelha e aspecto brilhante. Murcicarmina de Mayer, obj 40.

cerbar a criptococose [2,12]. Entretanto, muitos cães afetados não têm evidências de impedimento do sistema imunológico [12]. O exame imunoistoquímico para cinomose, uma importante doença imunossupressora no cão, foi negativo. $\mathrm{O}$ uso de corticosteróides no presente caso pode ter contribuído para o agravamento do quadro clínico. No entanto, o uso dessas drogas em associação com antifúngicos é recomendado por alguns autores [12].

O envolvimento das leptomeninges observado no presente caso é comum, refletindo um sítio de predileção [10]. A hidrocefalia não comunicante observada nesse cão, provavelmente estava associada à obstrução das aberturas laterais do quarto ventrículo, visto que este também estava dilatado e que não foi evidenciada obstrução do aqueduto mesencefálico.

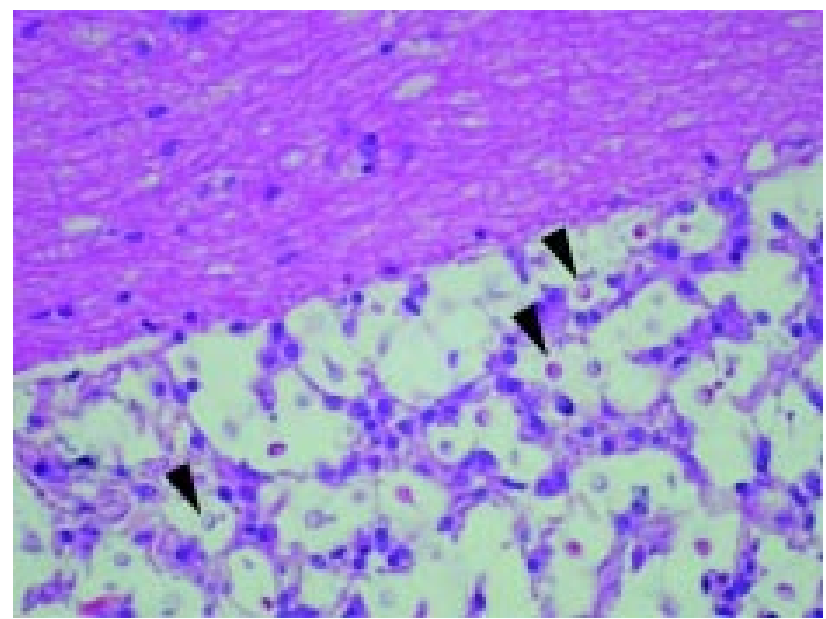

Figura 2. Leptomeninges apresentando numerosas estruturas encapsuladas, arredondadas a elípticas. HE, obj 20.

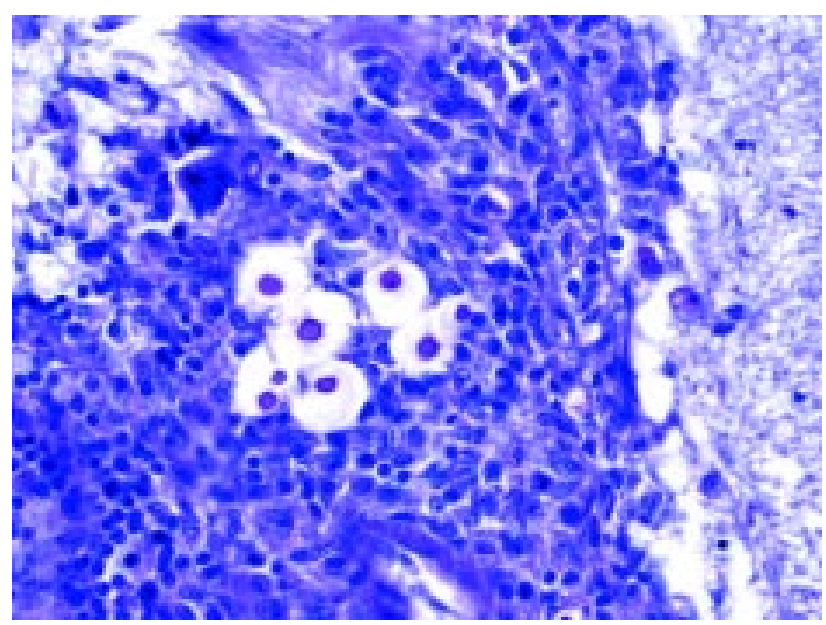

Figura 4. Estruturas capsulares positivas ao Ácido Periódico de Schiff em meio à meningite granulomatosa, obj 40.

A obstrução dessas estruturas é relacionada com a inflamação no sistema ventricular [13].

Em contato posterior, o proprietário relatou que era comum encontrar pombas se alimentando nos restos de ração deixados na vasilha que o cão utilizava, o que sugere o envolvimento dessas aves como possíveis fontes de infecção da doença [9].

Um estudo anteriormente realizado na cidade de Porto Alegre, partindo de amostras de cães com manifestações clínicas respiratórias e neurológicas, não revelou o envolvimento do Cryptococcus na etiologia destas enfermidades [7]. No entanto, o caso aqui apresentado indica que o agente representa risco à população de cães exposta aos propágulos fúngicos no Rio Grande do Sul e que este agente deve ser considerado em animais com sinais neurológicos. 


\section{REFERÊNCIAS}

1 Chandler F.W., Kaplan W. \& Ajello L.A. 1980. Colour Atlas and Textbook of the Histopathology of the Mycotic Diseases. London: Wolfe Medical Publications Ltd., 333p.

2 Honsho C.S., Mine S.Y., Oriá A.P., Benato N., Camacho A. A., Alessi A.C. \& Laus J.L. 2003. Criptococose sistêmica generalizada em cão após corticoterapia imunossupressora. Arquivo Brasileiro de Medicina Veterinária e Zootecnia. 55: 155-159.

3 Jergens A.E., Wheeler C.A. \& Collier L.L. 1986. Cryptococcosis involving the eye and central nervous system of a dog. Journal of the American Veterinary Medical Association. 1: 302-304.

4 Larsson C.E., Otsuka M., Michalany N.S., Barroa P.S.M., Gambale W. \& Safatle, A.M.V. 2003. Criptococose canina: relato de caso. Arquivo Brasileiro de Medicina Veterinária e Zootecnia. 55: 533-538.

5 Lavely J. \& Lipsitz D. 2005. Fungal infections of the central nervous system in the dog and cat. Clinical Techniques in Small Animal Practice. 20: 212-215.

6 Marcasso R.A., Sierra S., Arias M.V.B., Bracarense A.P.F.R.L., Yamamura A.A.M., Biasi F., Lopes B.A., Amude A.M. \& Cortêz D.E.A. 2005. Criptococose no sistema nervoso de cães - relato de três casos. Semina: Ciências Agrárias. 26: $229-238$.

7 Oliveira I.A., Nobre M.O. \& Ferreiro L. 2005. Pesquisa de criptococose em cães atendidos no Hospital de Clínicas Veterinárias da UFRGS, Porto Alegre, Brasil. Acta Scientiae Veterinariae. 33: 253-258.

8 O'Toole T.E., Sato A.F. \& Rozansky E.A. 2003. Cryptococcosis of the central nervous system in a dog. Journal of the American Veterinary Medical Association. 222: 1722-1725.

9 Passoni L.F.C. 1999. Wood, animals and human being as reservoirs for human Cryptococcus neoformans infection. Revista Iberoamericana de Micologia. 16: 77-81.

10 Summers B.A., Cummings J.F. \& De Lahunta A. 1995. Veterinary Neuropathology. St. Louis: Mosby, 527p.

11 Taboada J. \& Grooters A.M. 2005. Systemic mycoses. In: Ettinger S.J. \& Feldman E.C. (Eds). Textbook of Veterinary Internal Medicine. v.1. 6th edn. St. Louis: Elsevier Saunders, pp.671-640.

12 Thomas W.B. 1998. Inflammatory diseases of the central nervous system in dogs. Clinical Techniques in Small Animal Practice. 13: 171-172.

13 Zachary J.F. 2007. Nervous System. In: McGavin M.D. \& Zachary J.F. (Eds). Pathologic Basis of Veterinary Disease. 4th edn. St. Louis: Mosby, pp.833-871. 